\title{
NOTAS SOBRE EL USO DEL SELLO EN ELCHE
}

\author{
María Luisa CABANES CATALÁ \\ Ramón BALDAQUÍ ESCANDELL \\ Universidad de Alicante
}

El objeto de las presentes páginas es analizar el uso del sello en la villa de Elche, valiéndonos tanto de las menciones en fuentes documentales como de las improntas conservadas. La variedad de usos encontrados en una misma comunidad y su permanencia a lo largo del tiempo creemos que justifica la presente nota, que no tiene más finalidad que reunir las noticias dispersas que hemos podido localizar sobre el tema.

En el solar ilicitano encontramos vestigios del uso de sellar desde la Antigüedad. Entre los abundantes restos romanos hallados en las ruinas de la Alcudia de Elche, solar de la antigua Illici, han aparecido numerosas gemas incisas y algunas matrices en bronce para estampar marcas, seguramente en yeso, para sellar ánforas(1). Pero como nuestro objetivo es el estudio de la difusión y uso del sello, más que de los testimonios conservados, debemos limitarnos a los que encontramos en las edades Media y Moderna. Comenzando por los sellos de particulares, el más antiguo que encontramos en Elche parece ser el perteneciente a un Johan Pérez de Exia, de quien se conservan en el archivo municipal(2) y en el museo arqueológico(3), procedentes en ambos casos de las colecciones de Pedro lbarra, un grupo de improntas modernas, pero aparentemente hechas utilizando una matriz antigua. Sabemos que con este nombre existió en Elche un personaje, quizá aragonés, que otorgó testamento el 18 de octubre de 1295(4), de modo que acaso Ibarra dispusiese de una matriz del sello de este perso- 
naje, posiblemente depositada con él en su sepultura o conservada en la iglesia de Santa María, en donde parece que Johan Pérez de Exia fue enterrado.

De 1447 se conserva, en el archivo municipal de Barcelona, una carta con el sello del alfaquí de la morería de Elche, Mahomat Alhaig, con una representación de arabescos. Fue publicado y reproducido por Sagarra en su Sigil.lografia catalana(5) y se trata de un ejemplar notable, por cuanto de musulmanes conocemos muy pocos sellos, y ningún otro de origen valenciano.

Sin salir del grupo de los sellos de particulares, aunque ya en el siglo XVIII, sabemos que entre los bienes incluídos en 1743 en el vínculo fundado por el caballero don Francisco Xavier Tárrega en cabeza de su hijo don Antonio de Padua Tárrega y Malla, figura "un sello de plata con las armas de los Tárregas", tasado en diez reales(6). Y en el último cuarto del mismo siglo encontramos en poder de los descendientes de don Gregorio Ortiz de Beaumont una matriz con las armas del linaje navarro de Beaumont, del que descendía el noble ilicitano(7).

$Y$ asi mismo la utilización del sello es un uso generalizado entre las parroquias y conventos de Elche. Las dos parroquias de la villa, dedicadas a Santa María y al Salvador, junto con la de San Juan Bautista, correspondiente a la Universidad de San Juan, que contaba con ayuntamiento propio, poseen sello para validar sus documentos, aunque los testimonios que poseemos son muy tardíos. El sello parroquial más antiguo conservado en el archivo municipal de Elche corresponde a la iglesia de Santa María, es una impronta datada en 1689, procedente de una matriz que ya no volveremos a tener documentada(8). Desde 1785, fecha de la siguiente impronta localiza$\mathrm{da}$, hasta 1850 encontramos utilizada otra matriz, de la misma medida y con la misma representación de la anterior, aunque varía la leyenda(9). Por orden de antigüedad, la siguiente parroquia ilicitana es la del Salvador y conocemos varias improntas datadas entre 1770 y 1853(10), procedentes todas de la misma matriz. Finalmente, correspondientes a la parroquia de San Juan Bautista hemos hallado dos improntas de una matriz de buen arte y correcta factura, fechadas en 1845 y 1851 (11).

También poseyeron sello propio los tres conventos de la villa pero, como en el caso de las parroquias, los ejemplos que guarda el citado archivo son tardíos y se refieren fundamentalmente a los siglos XVIII y XIX. La impronta más antigua corresponde al convento de la Encarnación, de la orden de Santa Clara, y aunque carece de fecha precisa, el contenido del documento que valida permite datarla en la década de 1680; con la misma matriz se realiza otra impronta en 1725. A pesar de su mal estado de conservación, encontramos en ambas una representación hagiográfica de tipo gótico, de un sorprendente arcaísmo para la fecha de su realización(12). 
En cambio del convento de mercedarios de Santa Lucía se conservan nada menos que 10 improntas procedentes de tres matrices distintas, aunque todas con la misma representación, el escudo de la orden. En la primera mitad del siglo XVIII dos matrices se utilizan simultáneamente entre 1702 y 1754, desapareciendo a partir de este año una de ellas y quedando en uso la otra durante toda la centuria del setecientos. A partir de 1817 tenemos documentada la tercera matriz, seguramente abierta de poco tiempo antes(13). Por último, del sello del convento de franciscanos alcantarinos de San José hay un sólo ejemplar, fechado en 1718, con representación hagiográfica(14).

Como puede observarse, mientras que las noticias que poseemos de sellos de particulares se refieren exclusivamente a matrices de las que no conocemos detalles sobre su uso, del grupo de sellos eclesiásticos nos han llegado exclusivamente improntas utilizadas para validar documentos, sin que hallemos otros usos de las mismas(15). La forma usada no ha sido siempre la misma, alternando en ellas las biojival (de los sellos de la Encarnación y San José) y ovalada (usada por el convento mercedario y las tres parroquias). Mucha mayor es, sin embargo, la variedad de usos que encontramos en los sellos municipales, de los que nos ocuparemos a continuación.

Analizadas todas las noticias que hemos encontrado sobre el empleo del sello por parte del Consell ilicitano, observamos desde el principio una gran variedad de usos, lo que nos ha permitido su sistematización según aquéllos: vemos así el sello utilizado, además de para validar documentos, como símbolo de la autoridad y personalidad del municipio y como marca de propiedad y garantía de ingenuidad e integridad. Resulta esencial para todas estas funciones la permanencia del tipo a través del tiempo y la apertura de matrices.

La primera noticia documentada se refiere al sello como símbolo de la autoridad y personalidad del Consell y figura en la concesión a Murcia de los fueros y franquicias de Sevilla hecha por Alfonso el Sabio(16), concesión luego extendida a Elche por el infante don Manuel en 1270(17). En este documento, datado en Sevilla en 1266, el rey autoriza a la mencionada ciudad para tener un "seello de dos tablas", que deberían custodiar dos "omens bonos" del consejo(18).

La siguiente noticia de este tipo de uso es ya más de cien años posterior. En el acta del cabildo de 10 de mayo de 1383 se recoge el juramento de dos de los jurados, Gil Gastó y Garcia Rodrigues, ante el justicia Berenguer Quexans y los jurados Benito Ferri y Benet Navarro. Tras la jura se añade: 
E fon-los librat per los dits jurats del ayn pasat a aquestos que de present són elets lo sagell de la vila, que es de llautó, e la clau de la torre on se te consell especial(19).

Dentro de este mismo apartado, ya en el último cuarto del siglo $\mathrm{XV}$, en la sesión del consejo del 25 de junio de 1481, se acuerda enviar a los mensajeros que tiene la villa en la corte, diversos traslados de documentos, que han solicitado así como uno de los sellos del consell, pedido también por ellos mismos, para que puedan emitir cartas en nombre de éste:

Item, lo dit consell hordena que transllat autèntich de la procura de mossèn Johan de Càrdenes que aquell tenia de la senyora reyna pera pendre la possesió de la dita vila e lo acte del sagrament que aquell féu en ànima de la dita senyora de servar furs e priviletgis e costums de la dita vila e fer servar aqu[e]ls a la dita senyora, los quals per los dits misatgers son demenats, e translat de dos capituls contenguts en hun priviletgi de la dita senyora, per la hu dels quals la dita senyora en sa fe real promés servar furs e priviletgis e costums de la dita vila, conferma aquells, que tot sia tramés per hun coreu als dits misatgers e per semblant los sia tramés hun sagell de dos sagells que.l dit consell té per sagelar les letres, ab lo qual haquels puxen sagellar letres que dien que an menester fer de part del dit consell a diverses persones. Aquel dit correu sia pagat per lo clavari del dit consell e mostrada cautela li sia pres en compte(20)

Aún en el siglo XVIII encontramos que conserva su fuerza este aspecto simbólico del sello. Durante el motín antiseñorial que tuvo lugar en Elche en abril de 1766, entre las medidas que tomaron los amotinados para suprimir la Universidad de San Juan, antigua aljama morisca segregada de la villa y cuyo gobierno controlaba el marqués de Elche, figura, además de la demolición de los arcos y puertas que separaban una de otra, la incautación del sello:

En este día dies y ocho, a instancias del expresado motín, passó dicho alcalde a entregarse del sello de la universidad de San Juan, para que no se usase más de él, y que en adelante se sellasen las boletas para la tropa de los exércitos de su Magestad con el sello de la villa(21).

Del segundo aspecto, el sello como garante de la validez de los documentos, la primera mención de la que tenemos noticia corresponde a un documento datado el 23 de noviembre de 1301, por el que el consell ilicitano nombra sus representantes a Bernat Pasqual y Pere Roys d'Ancano para acudir ante Guillem de Vilaragut, documento copiado también en el libro de privilegios de la villa y que en el translado que nos lo ha conservado es descrito así: 
Sàpien quants esta carta veuran et oyran que en presència de mi, Pere Tolsà, notari públich de Oriola, et dels testimonis dejús escriptes a azò demanats et pregats, En Bernat Pascual et En Pere Ruys d'Ancano, veyns d'Elch, presentaren et feren liger una carta escripta en paper, oberta et segellada ab lo segell del dit loch de Elch a.N Guillem de Vilaragut...(22)

La siguiente mención que hemos hallado del sello de la villa en función de validación documental data del 6 de noviembre de 1415. Con esta fecha el justicia y jurados de la villa extienden una certificación al comerciante Anthony de Quexans, de las franquicias comerciales concedidas por los reyes de la Corona de Aragón a Elche, validada con sello pendiente de la villa:

En testimoni de les quals coses lo present al dit nostre vehi éser liurada ab lo sagell de nós dit justícia en pendent sagellada e signada de mà del dit notari dejús scrit(23).

Durante los períodos históricos en que la villa forma parte de un señorío, el uso de su sello, reflejo de su personalidad jurídica, convive con el sello propio de sus señores. Mientras la villa de Elche y lugar de Crevillente estuvieron infeudados a la ciudad de Barcelona, entre 1391 y 1460, encontramos que el baile nombrado por ésta utiliza en 1449 un sello redondo que presenta un escudo alosanjado con las armas de aquélla, señora de ambos lugares(24). Durante este mismo período la villa continúa usando su sello propio para validar sus documentos.

Con la misma función utiliza sus sellos la aljama de los moros de Elche en las misivas que envía al consell de Barcelona sobre diversos asuntos, datadas en 1446, 1449 y 1451. La tipología de éstos nos lleva a suponer que la aljama no poseía sello propio y utilizaba para validar sus documentos bien el de alguno de sus miembros (caso del alfaquí Mahomat Alhaig, de quien ya hemos hablado) o de algún comerciante o persona que gozase de su confianza(25).

Durante el señorío de los Manuel, encontramos el primer testimonio del uso del sello como marca de propiedad y, al mismo tiempo -en este casogarantía de integridad y autenticidad de una medida noticia relativa al sello de los señores. En 1285 la condesa doña Beatriz, mujer del infante don Manuel, dispone que se hagan nuevas medidas para los partidores del agua de las acequias de Marchena y Alvanilla, que deberían de ser de hierro y marcadas con su sello:

...tiengo por bien que Nicolás de Luna, maestro de las aguas, fiziesse de nuevo el partidor de Marchena et el partidor de Alveniella, porque cada uno d'ellos oviessen su derecho, según las medidas que 
yo mandé fazer de ferro, seelladas con mío seello, de las quales es la mayor del partidor de Marchena y la menor del partidor de Avenella, que tiene el concejo de Elche(26).

Con la misma función, vemos usado el sello de la villa en 1572, cuando las autoridades municipales lo hacen estampar en la campana fundida ese año para la torre del consell(27).

Asimismo tenemos constancia de la apertura de matrices por parte del consell. A mediados del siglo XV, en 1440, en la sesión celebrada el 30 de julio, entre los asuntos tratados, se acordó encargar una nueva matriz sigilar para el "consell" de la villa, por haberse perdido la anterior. Se especifica que deberá ser semejante a la desaparecida:

Item(28), lo dit honorable consell, attenent que lo sagell de la dita vila que.l consell tenia pera segellar lletres no pot atrobar. Per tal hordena que sia fet fer hun altre segell, a mostra de una empremta del altre. E ço que costarà lo dit segell que lo pac lo jurat e clavari, e montrant (sic) cautela li serà pres en compte(29).

La pervivencia del tipo a través del tiempo resulta fundamental para que el sello pueda desempeñar sus funciones de validación documental y representación de la personalidad jurídica del titular. La primera impronta que encontramos del sello de la villa es de 1458, recogida en el catálogo de don Antonio de la Torre y del Cerro(30). Del mismo tipo y con la misma fecha, Julio González ofrece un dibujo en su conocido trabajo sobre los sellos concejiles medievales(31). Se trata de una representación que en origen era de tipo monumental pero que en 1400 ya ha pasado a ser una representación heráldica(32). La siguiente impronta con que contamos es del siglo XVII: es un sello de forma redonda, de $40 \mathrm{~mm}$., improntado en oblea roja y papel, sobre un documento datado el 20 de noviembre de 1628(33). Tiene la misma representación heráldica que encontramos en los sellos medievales ya citados y en el estampado en 1572 en la campana del concejo. Ésta será la tipología de los del "consell" ilicitano, hasta que en el sigo XIX se incorporó a la sigilografía municipal el actual escudo, que encontramos por vez primera en 1621, decorando la cubierta de la crónica ilicitana terminada en ese año por Cristóbal Sanz, el cual se difunde durante los siglos XVII y XVIII y en el que se incorporan diversos elementos tomados de las monedas que el arzobispo de Tarragona Antonio Agustín atribuyó a Illici en sus Diálogos de las medallas de las colonias, municipios y pueblos antiguos de España, en alusión al pasado romano de la ciudad(34). Este es el escudo que ofrece el sello de tinta remitido por la villa en obediencia a la orden de 3 de septiembre de 1876, y que se conserva en la colección de sellos municipales que custodia el Archivo Histórico Nacional. 
Frente a la escasez de noticias de los siglos precedentes a partir de mediados del XIX y hasta los años veinte de este siglo menudean las noticias sobre elaboración de matrices sigilares. En acta del 13 de julio de 1848, acuerda el cabildo encargar una matriz en bronce del sello de la villa según está prevenido por real orden(35). En 1889 se adquiere otro sello para las oficinas del ayuntamiento, con la inscripción "secretaría del ayuntamiento"(36). En 1891, el ayuntamiento adquiere cinco sellos para las tenencias de alcalde(37), las cuales fabricadas en metal se echaron de menos tres años después(38).

Hasta aquí las noticias que hemos podido recoger sobre el uso del sello en Elche hasta el siglo XIX, donde se aprecia una gran variedad y difusión en esta comunidad, por parte de todos los grupos sociales y confesionales, destacando la continuidad de tipos y usos a lo largo del período estudiado. 


$$
\text { . }
$$




\section{NOTAS}

(1) Aureliano IBARRA Y MANZONI, IIlici, su situación y antigüedades. Alicante 1879, (ed. fac. Alicante, 1981), pags.148-150 y 160-161.

Pedro IBARRA RUIZ, Elche. Materiales para su historia. Cuenca, 1926, p. 82.

Rafael RAMOS FERNANDEZ, La ciudad romana de Illici. Alicante, 1975, p. 252.

(2) $\mathrm{M}^{\mathrm{a}}$ Luisa Cabanes Catalá y Ramón Baldaqui Escandell, Catálogo de sellos del Archivo Histórico Municipal de Elche (en prensa), sello n 75

(3) Pedro J. RIPOLL VIVANCOS y Araceli HOFFMAN JAVALOYES, "Inventario de los fondos sigilográficos del museo arqueológico municipal" en Pobladores de Elche, no 12 (1990) p. 9, número 7.

(4) Anna María ALVAREZ FORTES, "El sentit de la mort per a l'home de l'Elx medieval" en Festa d'Elx, no 42 (1990) p. 33-34.

(5) Ferran DE SAGARRA Y DE SISCAR, Sigil.lografia catalana. Inventari, descripció i estudi dels segells de Catalunya. Vol. II. Barcelona, 1922, p. 241, número 1.815 y lám. CLXXXII.

(6) Archivo Municipal de Elche (en adelante AME), sig. b/193, Genelogías de Tárrega, Malla, Maza de Lizana, Caro, Sequira y otros, f. 36v. Se trata de un libro de memorias familiares de la familia Tárrega iniciado a mediados del siglo XVIII, continuado en el siglo XIX con genealogías de las restantes familias enunciadas.

Este mismo legado se encuentra en la "Sentencia de compromiso y división y partición de los bienes y herensia del doctor don Francisco Xavier Tárrega", pasada ante el notario Carlos Pasqual el 11 de diciembre de 1743, en la que figura el asunto siguiente:

"Otrosi: un sello de armas de los Tárregas, diez reales".

Vid. Archivo Municipal de Elche, Sección Protocolos Notariales, Protocolos de Carlos Pasqual, 1743, f. 354.

(7) $\mathrm{M}^{\mathrm{a}}$ Luisa CABANES CATALÁ y Ramón BALDAQUí ESCANDELL, Catálogo de sellos del Archivo Histórico Municipal de Elche (en prensa), número 67. Se trata de una impronta realizada como prueba en 1783, junto a la cual una mano contemporánea realizó la siguiente anotación:

"En 1778 lo tenía Da María Francisca Capdevila, viuda de don Gregorio Ortiz de Beaumont en Elche, y ahora sus hijos en 1783.

Lo tiene en éste de 1783 don Diego Ortiz, guardia de Corps, otro de sus hijos". 
(8) Mำ Luisa CABANES CATALÁ y Ramón BALDAQUí ESCANDELL, Catálogo de sellos del Archivo Municipal de Elche (en prensa), número 247. De los mismos autores, "Sellos parroquiales de Santa María conservados en el archivo municipal de Elche", en Festa d'Elx, 41, 1988, pp. 30-39, número 1.

(9) Ma Luisa CABANES CATALÁ y Ramón BALDAQUÍ ESCANDELL, Catálogo de sellos del Archivo Histórico Municipal de Elche (en prensa), números 208 a 220. Id, "Sellos parroquiales de Santa María conservados en el archivo municipal de Elche", en Festa d'Elx, 40, 1988, números 2 al 14.

(10) María Luisa CABANES CATALÁ y Ramón BALDAQUÍ ESCANDELL, Catálogo de sellos del Archivo Histórico Municipal de Elche (en prensa), números 203 a 206: la impronta número 206 carece de data precisa y aparece fechada mediante nota manuscrita moderna en el siglo XIX. Vid. también Araceli GUGLIERI NAVARRO, Catálogo de sellos de la sección de sigilografía del Archivo Histórico Nacional, Valencia, 1974, t. II, p. 537, número 1.429.

(11) María Luisa CABANES CATALÁ y Ramón BALDAQUÍ ESCANDELL, Catálogo de sellos del Archivo Histórico Municipal de Elche (en prensa), números 201 y 202.

(12) María Luisa CABANES CATALÁ y Ramón BALDAQUÍ ESCANDELL, Catálogo de sellos del Archivo Histórico Municipal de Elche (en prensa), números 270 y 271.

(13) María Luisa CABANES CATALÁ y Ramón BALDAQUí ESCANDELL, Catálogo de sellos del Archivo Histórico Municipal de Elche (en prensa), números 273 al 282.

(14) María Luisa CABANES CATALÁ y Ramón BALDAQUí ESCANDELL, Catálogo de sellos del Archivo Histórico Municipal de Elche (en prensa), número 272.

(15) Sin embargo, tenemos constancia de la presencia en Elche de un sello eclesiástico utilizado como garante de la autenticidad de unas reliquias, procedente como los anteriores de las colecciones de Pedro lbarra. Vid. Pedro J. RIPOLL VIVANCOS y Araceli HOFFMAN JAVALOYES, "Inventario de los fondos sigilográficos del Museo Arqueológico Municipal". En Pobladores de Elche, no 12, 1987 , p. 7.

(16) Mำ Luisa CABANES CATALÁ, El libro de privilegios de la villa de Elche (en prensa), doc. número 3.

(17) Mำ Luisa CABANES CATALÁ, El libro de privilegios de la villa de Elche (en prensa), doc. número 10.

(18) Mํ. LUISA CABANES CATALÁ, El libro de privilegios de Elche (en prensa), doc. 3: Otrosí, les damos seello de dos tablas et tenemos por bien que las tengan dos omens bonos que les escojeren el conzejo con su consentimiento d'aquel que estuviere y por nos, et que tenga el uno la una tabla et el otro la otra.

(19) Aureliano IBARRA Y MANZONI, Illici. Su situación y antiguedades. p. 289

(20) A.M.E., Cabildos de 1481, acta del 25 de junio de 1481

(21) A. M. E., Papeles Varios de Pedro Ibarra, t. $3^{\circ}$, f. $248 \mathrm{v}$. La misma noticia, aunque tomada de otra fuente, ofrece Pedro RUíz TORRES, "Los motines de 1766 y los inicios de la crisis del 'Antiguo Régimen'", en Bartolomé CLAVERO et al., Estudios sobre la revolución burguesa en España (Madrid, 1979), p. 84.

(22) $\mathrm{M}^{2}$ Luisa CABANES CATALÁ, El libro de Privilegios de Elche (en prensa), doc. 
70. En el documento que contiene el nombramiento de dichos procuradores (ibjdem, doc. 69) se añade la siguiente cláusula de sellado:

En testimoni de la qual cosa vos donam esta carta, segellada ab nostre segell.

(23) Pedro IBARRA Y RUIZ, "Elig. Noticia de algunas instituciones y costumbres de la Edad Media", p. 31, publicado como apéndice en la obra del mismo autor Elche. Materiales para su historia. Cuenca, 1926.

(24) Mª Luisa CABANES CATALÁ y Ramón BALDAQUí ESCANDELL, "Los sellos municipales valencianos del siglo XV", en 1490 En el umbral de la modernidad, Valencia, 1994, vol. I, p. 291. Se trata de un sello que valida un documento fechado en Elche el 4 de junio de 1449, por el que el baile de Elche y Crevillente en nombre de la ciudad de Barcelona comunica al justicia de Cocentaina haberse subastado ciertos bienes de un moro llamado Muça y depositado el importe, a fin de satisfacer ciertas deudas contraídas por el mismo.

(25) Los sellos aludidos fueron publicados por Ferran DE SAGARRA Y DE SISCAR, Sigil.lografia catalana, vol. II. Barcelona, 1922, p. 241, núms. 1.814a y 1.816 y lám. CLXXXII.

(26) Ma Luisa CABANES CATALÁ, El libro de privilegios de la villa de Elche (en prensa), doc. 33, Villena, 18 de octubre de 1285.

(27) Aureliano IBARRA Y MANZONI, Illici..., p. 288-289

(28) Al margen izquierdo: segell

(29) A. M. E., Cabildos, libro 12, acta del 30 de julio de 1440

(30) Antonio de la TORRE Y DEL CERRO, "La colección sigilográfica del archivo de la catedral de Valencia", en Archivo de arte valenciano, año Vl, (1920), p. 53.

(31) J. GONZALEZ GONZALEZ, "Los sellos concejiles de España en la Edad Media" en Hispania, V (1945) p. 371 y 382.

(32) En forma heráldica aparece ya en los escudos de las cruces de término de la villa de 1400 y 1472 y posteriormente en la puerta de la casa de la "cort del justícia" de 1547. El fenómeno de las representaciones de origen monumental en los sellos municipales, que posteriormente pasan a ser heráldicas, ocurre contemporáneamente en otras varias poblaciones valencianas, como ya estudiamos en otro trabajo: cfr. $M^{a}$ Luisa CABANES CATALÁ y Ramón BALDAQUí ESCANDELL, "Los sellos municipales valencianos del siglo XV", pp. 295, 298299.

(33) Mª Luisa CABANES CATALÁ y Ramón BALDAQUí ESCANDELL, Catálogo de sellos del Archivo Histórico Municipal de Elche, (en prensa) sello no 50.

(34) Cfr. Aureliano IBARRA Y MANZONI, llici. Su situación y antigüedades, p. 292.

(35) A.M. E.- Cabildos, año 1848, acta del 13 de julio

(36) A. M. E.- Cabildos, año 1889, acta de 28 de febrero

(37) A. M. E.- Cabildos, año 1891, acta del 4 de abril

(38) A. M. E.- Cabildos, año 1894, acta del 21 de julio 